Cite as: Zogheib, B., Rabaa'i, A., Zogheib, S., \& Elsaheli, A. (2015). University student perceptions of technology use in mathematics learning. Journal of Information Technology Education: Research, 14, 417-438. Retrieved from http://www.jite.org/documents/Vol14/JITEv14ResearchP417-438Zogheib2039.pdf

\title{
University Student Perceptions of Technology Use in Mathematics Learning
}

\author{
Bashar Zogheib and Ahmad Rabaa'i \\ American University of Kuwait, Salmiya, Kuwait \\ bzogheib@auk.edu.kw; arabaai@auk.edu.kw
}

$\begin{array}{cc}\text { Salah Zogheib } & \text { Ali Elsaheli } \\ \text { King Abdulaziz University, Jeddah, } & \text { American University of Kuwait, } \\ \text { Kingdom of Saudi Arabia } & \text { Salmiya, Kuwait } \\ \text { salahzogheib@hotmail.com } & \text { aelsaheli@auk.edu.kw }\end{array}$

Abstract

Although most universities and educators are relying on implementing various technological tools in the curriculum, acceptance of such tools among students is still not sufficient. The Technology Acceptance Model (TAM) has been widely used by researchers to test user's acceptance of technology in business, education and other domains. This research study is an attempt that tests the integration of TAM and user satisfaction in the educational field. It particularly investigates students' acceptance to use MyMathLab, a technological tool, in university math classes in the Middle East. Structural equation modelling with various constructs was used. Findings support the theoretical model showing the great influence of user satisfaction on perceived ease of use and subjective norm on behavioural intention. The findings of this study also demonstrate that selfefficacy, user satisfaction, subjective norms, perceived usefulness, perceived ease of use, and students' attitude constructs all have a positive impact on students' behavioural intentions to adopt and use technological tools in a mathematics class room. Findings of this research have greater implications for educators and students worldwide.

Keyword: TAM, MyMathLab, university, students, math, self-satisfaction.

\section{Introduction}

Higher education institutions have implemented different technologies to provide teachers and students with many interesting tools that

Material published as part of this publication, either on-line or in print, is copyrighted by the Informing Science Institute. Permission to make digital or paper copy of part or all of these works for personal or classroom use is granted without fee provided that the copies are not made or distributed for profit or commercial advantage AND that copies 1) bear this notice in full and 2) give the full citation on the first page. It is permissible to abstract these works so long as credit is given. To copy in all other cases or to republish or to post on a server or to redistribute to lists requires specific permission and payment of a fee. Contact Publisher@InformingScience.org to request redistribution permission. can be used to improve the teachinglearning process (Martín-Blas \& Serrano-Fernández, 2009). However, despite the strong presences of information and communication technology (ICT) in classrooms, studies have shown that ICT is underused (Ruthven, 2009).

For instance, although institutions have made large investments in educational technology, many technologies have 
been underutilised or abandoned completely, due to limited user acceptance (Liu, Liao \& Pratt, 2009; Teo, 2009), for example, SMART notebook. Similarly, Imtiaz and Mirhashemi (2013, p. 23) argued that many advantages of technology in education have been realized, but there still remain many hindrances and barriers in technology adoption and use in education. Imtiaz and Mirhashemi (2013, p. 23) stipulated that this has led to a less than expected implementation of technology in education.

This study tries to bridge the gap identified in prior research (e.g., Liu et al., 2009; Ruthven, 2009; Teo, 2009) in relation to technology adoption and use in education. The current study proposes and empirically tests an integrated theoretical model of university students' acceptance and intentions to use a technological tool, named MyMathLab, based on an extended version of the technology acceptance model (TAM) and user satisfaction.

Recently, researchers argued that the models and theories that developed from the body of research within the business contexts could be applied to understanding technology acceptance in educational contexts (Teo, 2013). Among the most popular models in technology acceptance research, the technology acceptance model (TAM) (Davis, 1989) has been found to be a robust model for understanding the factors that affect users' intention to use technology in education (Teo, 2012). In fact, TAM has become one of the most widely used models in technology embedded education research (Kiliç, 2014).

This study aims at investigating and assessing the factors that determine the adoption of technological tools in mathematics among university students. The main research question this paper explores is, What are the main factors that determine university students' attitudes toward adopting technological tools in learning?

This paper is arranged into six sections. Following the Introduction, the second section provides a brief review of prior studies in technology adoption in general, technology adoption in education, and the exemplar technological tool used for investigation in this study. The third section discusses the research model and hypotheses. Section four describes the research method. The data analysis is presented in section five, and, finally, section six discusses the findings and concludes the paper.

\section{Literature Review}

\section{Technology Acceptance and Adoption}

Researchers in the field of Information Systems (IS) have for long been interested in investigating the theories and models that can predict and explain behaviour (Venkatesh, Morris, Davis, \& Davis, 2003). Various models were developed, such as the Theory of Reasoned Action (TRA) (Fishbein \& Ajzen, 1975), Innovation Diffusion Theory (IDT) (Rogers, 1962, 1995), Theory of Planned Behaviour (TPB) (Ajzen, 1991), Diffusion of Innovation (DOI) (Rogers, 1995), and Technology Acceptance Model (TAM) (Davis, 1986). Each model has its own independent and dependent variables for user acceptance and there are some overlaps. However, most of the IT adoption works conducted earlier have adopted the technology acceptance model (TAM) to examine the user's intention for acceptance of technology. In their study of a total of 500 survey questionnaires, Adesina and Ayo (2010) found that TAM is the most widely used model for technology adoption.

TAM was developed by Davis (1986) to theorize the usage behaviour of computer technology. TAM was derived from another popular theory called theory of reasoned action (TRA) from the field of social psychology which explains a person's behaviour through their intentions. Intentions in turn are determined by two constructs: individual attitudes toward the behaviour and so- 
cial norms, or the belief that specific individuals or a specific group would approve or disprove of the behaviour. While TRA was developed to explain general human behaviour, TAM specifically explains the determinants of computer acceptance that are general and capable of explaining user behaviour across a broad range of end-user computing technologies and the user population (Davis, Bagozzi, \&Warshaw, 1989). TAM breaks down the TRA's attitude construct into two constructs: perceived usefulness (PU) and perceived ease of use (EU) to explain computer usage behaviour. In fact, TAM specifically explains the determinants of information technology enduser's behaviour towards information technology (Saade, Nebebe, \& Tan, 2007). In TAM, Davis (1989) proposes that the influence of external variables on intention is mediated by perceived ease of use (PEU) and perceived usefulness (PU). TAM also suggests that intention is directly related to actual usage behaviour (Davis et al., 1989).

While TAM has received extensive support through validations, applications, and replications for its power to predict use of IS and is considered to be the most robust and influential model explaining IS adoption behaviour (Davis, 1989; Davis et al., 1989; Lu, Yu, Liu, \& Yao, 2003), it has been found that TAM excludes some important sources of variance and does not consider challenges such as time or money constraints as factors that would prevent an individual from using an information system (Al-Shafi \& Weerakkody, 2009). In addition, TAM has failed to provide meaningful information about the user acceptance of a particular technology due to its generality (Mathieson, Peacock, \& Chin, 2001). Davis et al., (1989) compared the TAM with TRA in their study. The confluence of TAM and TRA led to a structure based on only three theoretical constructs: behaviour intention (BI), perceived usefulness (PU) and perceived ease of use (PEOU). Social norms (SN) were found to be weak as an important determinant of behavioural intention. While TRA and TPB theorised social norms as an important determinant of behavioural intention, TAM does not include the social norms such as influence of social and control factors on behaviour. This is significant, as the model will miss a core and critical component of technology acceptance, since these factors are found to have a significant influence on IT usage behaviour (Mathieson, 1991; Taylor \& Todd, 1995) and indeed are important determinants of behaviour in the TPB (Ajzen, 1991).

For instance, researchers have found that the original TAM variables may not adequately capture key beliefs that influence consumer attitudes toward e-commerce, (for example see Pavlou, 2003). As a result, TAM has been revised in many studies to fit a particular context of technology being investigated. One important and well-received revision of TAM has been the inclusion of social influence processes in predicting the usage behaviour of a new technology by its users (Venktatesh \& Davis, 2000). Legris, Ingham, and Collerette (2003) suggested that TAM deserves to be extended, by integrating additional factors, to facilitate the explanation of more than 40 percent of technology acceptance and usage. Other studies (e.g., Sun \& Zhang, 2006; Thompson, Compeau, \& Higgins, 2006) have suggested the extension and refinement of the technology acceptance models to enhance it generalizability. Thompson et al. (2006) argued that, considering the evolving new technologies, perceived ease of use and perceived usefulness are not the only suitable constructs that determine technology acceptance. Moreover, Agarwal and Prasad (1998) suggested including more dimensions, with other IT acceptance models in order to enhance its specificity and explanatory utility.

It is believed that the findings of this study will help decision makers in higher education institutions to gain a better understanding of the factors that determine student's adoption of these tools in classrooms and lead to a better implementation, investment, and benefit in the educational field. 


\section{Technology Acceptance and Adoption in Education}

Recently, various papers have been published on the context of application of TAM in higher education (e.g. Teo, 2009, 2010, 2011a, 2011b). A number of studies have used TAM to examine learners' willingness to accept e-learning systems (e.g., Al-Adwan, Al-Adwan, \& Smedley, 2013; Shah, Iqbal, Janjua, \&Amjad, 2013; Sharma \& Chandel, 2013; Shroff, Deneen, \& Ng, 2011; Tabak \& Nguyen, 2013) or to predict learners' intentions to use an online learning community (Liu et al., 2009). Some papers focused on validating TAM on specific software which is applied in higher education. For example, Escobar-Rodriguez and Monge-Lozano (2012) use TAM for explaining or predicting university students' acceptance of the Moodle platform, while Hsu, Wang, and Chiu (2009) performed an empirical study to analyse the adoption of statistical software among online MBA students in Taiwan. While some studies report that perceived usefulness and perceived ease of use impact attitude toward technology use and behavioural intention to use technology (e.g., Rasimah, Ahmad, \& Zaman, 2011; Sumak, Hericko, Pusnik \& Polancic, 2011; Teo, 2011a), Grandon, Alshare, and Kwan (2005) argued that e-learning self-efficacy was found to have indirect effect on students' intentions through perceived ease of use. Also, Mungania and Reio (2005) found a significant relationship between dispositional barriers and e-learning selfefficacy. They argued that educational practitioners should take into consideration the learners' dispositions and find ways through which e-learning self-efficacy could be improved.

Dasgupta, Granger, and McGarry (2002) analysed the acceptance of a courseware management technology (e-collaboration tool) by undergraduate students. They found that the user year in school was a significant determinant of the use of this technology. Also, Selim (2003) investigated TAM with web-based learning. The author proposed the course website acceptance model (CWAM) and tested the relationships among perceived usefulness, perceived ease of use, and intention to use with university students. The results of his study indicated that the model fits the collected data. Additionally, Selim argued that usefulness and ease of use are significant determinants of the acceptance and use of the course website. By integrating TAM with motivational theory, Lee, Cheung, and Chen (2005) studied university students' adoption behaviour towards an Internet-based learning medium (ILM) introducing TAM. The authors included perceived enjoyment as an intrinsic motivator in addition to perceived usefulness and perceived ease of use. The results indicated that perceived usefulness and perceived enjoyment had an impact on both students' attitude toward and intention to use ILM. However, perceived ease of use was found to be unrelated to attitude.

Phuangthong and Malisawan (2005) argued that TAM was helpful to understand factors affecting mobile learning adoption with $3^{\text {rd }}$ generation mobile telecommunication $(3 \mathrm{G})$ technology. Drennan, Kennedy, and Pisarski (2005) examined the factors affecting student satisfaction with flexible online learning and identified three key student attributes of student satisfaction: (1) positive perceptions of technology in terms of ease of access, (2) use of online flexible learning material, and (3) autonomous and innovative learning styles. Additionally, Torun, Ilgaz, and Usluel (2006) examined the perceptions of teachers in relation to using technology in classrooms. The authors found that perceived ease of use and perceived usefulness are important predictors of effective technology use. Elwood, Changchit, and Cutshall (2006) investigated students' perceptions of a laptop initiative in higher education. They found that the external factor "perceived change" is relevant to understand the acceptance of technology within the university environment.

Ngai, Poon, and Chan (2007) investigated the factors that influence WebCT use in higher education institutions in Hong Kong using the TAM model. They extended the model to include a new factor, "technical support". The results revealed that technical support is an important direct factor in the feeling that the system is easy to use and is useful. Moreover, using the extended TAM2, Van Raaij and Schepers (2008) researched the acceptance and usage of a virtual learning environment in China, and the results indicated that perceived usefulness has a direct effect on the 
use of virtual learning environments (VLE). Perceived ease of use and subjective norms had only an indirect effect on perceived usefulness. It was also demonstrated that new variables related to personality traits, like being innovative and feelings of anxiety towards the computer, had a direct effect on perceived ease of use. Gibson, Harris, and Colaric (2008) studied the degree to which TAM was able to adequately explain faculty acceptance of online education. Results indicate that perceived usefulness is a strong indicator of faculty acceptance; however, perceived ease of use offers little additional predictive power beyond that contributed by perceived usefulness of online education technology.

Moreover, Shen and Eder (2009) examined students' intentions to use the virtual world Second Life for education and investigated factors associated with their intentions. Results suggested that perceived ease of use affects user's intention to adopt Second Life through perceived usefulness. Computer self-efficacy and computer playfulness were also significant antecedents to perceived ease of use of virtual worlds. Based on TAM, Teo (2009) investigated teacher candidates in Singapore. The study found that technology acceptance of teachers increased their effective technology use in their classes. Additionally, Al-hawari and Mouakket (2010) analysed the significance of TAM factors in the light of some external factors on students' e-retention and the mediating role of e-satisfaction within e-learning context. They found significant relationships between these factors and indicated that further testing across different countries is needed to identify other external factor that might influence IT acceptance. Also, Waheed and Jam (2010) tested the teachers' acceptance of implementing a web-based learning environment based on TAM. The results of the study support that teachers are accepting implementing the new virtual based learning system for better productivity of teachers, students, and institution.

Sumak et al. (2011) found that perceived usefulness and perceived ease of use were factors that directly affected students' attitude, and perceived usefulness was the strongest and most significant determinant of students' attitude toward using technology in learning, while Wu and Gao (2011) identified perceived enjoyment as a factor in predicting attitude and behavioural intentions to the use of clickers in student learning. Based on TAM, Wong, Teo and Russo (2012) explored the role of gender and computer teaching efficacy as external variables in technology acceptance in Malaysia. The authors found that TAM was adequately explained by the data. The model accounted for 36.8 percent of the variance in intention to use computers among student teachers.

\section{MyMathLab}

One technological tool/platform that can be used in online mathematics classrooms is MyMathLab. MyMathLab is an innovative series of text-specific online courses that is available for Pearson textbooks in mathematics and statistics for college, high school, and middle school classes. It provides students with a study plan for each chapter which helps them in organizing their ideas and the concepts they learned in class. It also provides instructors with a tool that minimizes cheating. It assigns problems that are different from one student to another. MyMathLab helps students to identify their difficulties and allows for more practice depending on the students' level. It also has a bank of questions that gives the instructor the freedom to choose a variety of questions to create homework, quizzes, and tests. The exercises are similar to those in the textbook. However, the homework exercises get regenerated for unlimited time until the students obtain the right answer. Moreover, the exercises are linked to interactive learning resources such as videos or similar examples. This specific option is a powerful source of help for online students. It also has video lectures that provide the student with an instructor that is explaining the topics he/she has difficulties with.

MymathLab has a grade book that tracks students' results on tests and homework. However, tests have different settings from homework. Tests follow a multiple choice format. Students are allowed to answer each question only once. 
In order for the students to access MyMathLab, they are required to buy a brand new textbook with an access code or just buy the access code alone. However, the majority of students prefer buying the book because it costs just a bit more than buying the code alone. Buying the access code alone will give students access to the e-book and not to the print version. This means students who buy the book bundled with the access code will have access to the e-book too.

\section{Research Model and Hypotheses Development}

The research model to be tested in this study is presented in Figure 1. In this model, the latent variables (exogenous constructs) self-efficacy, subjective norm and user satisfaction have direct effect on the latent variables perceived ease of use and perceived usefulness that are considered to be endogenous variables. Perceived ease of use and perceived usefulness are also considered as exogenous variables as they affect the endogenous variables attitude and behavioural intention. The arrows between a latent variable and its corresponding indicators represent measurement validity.

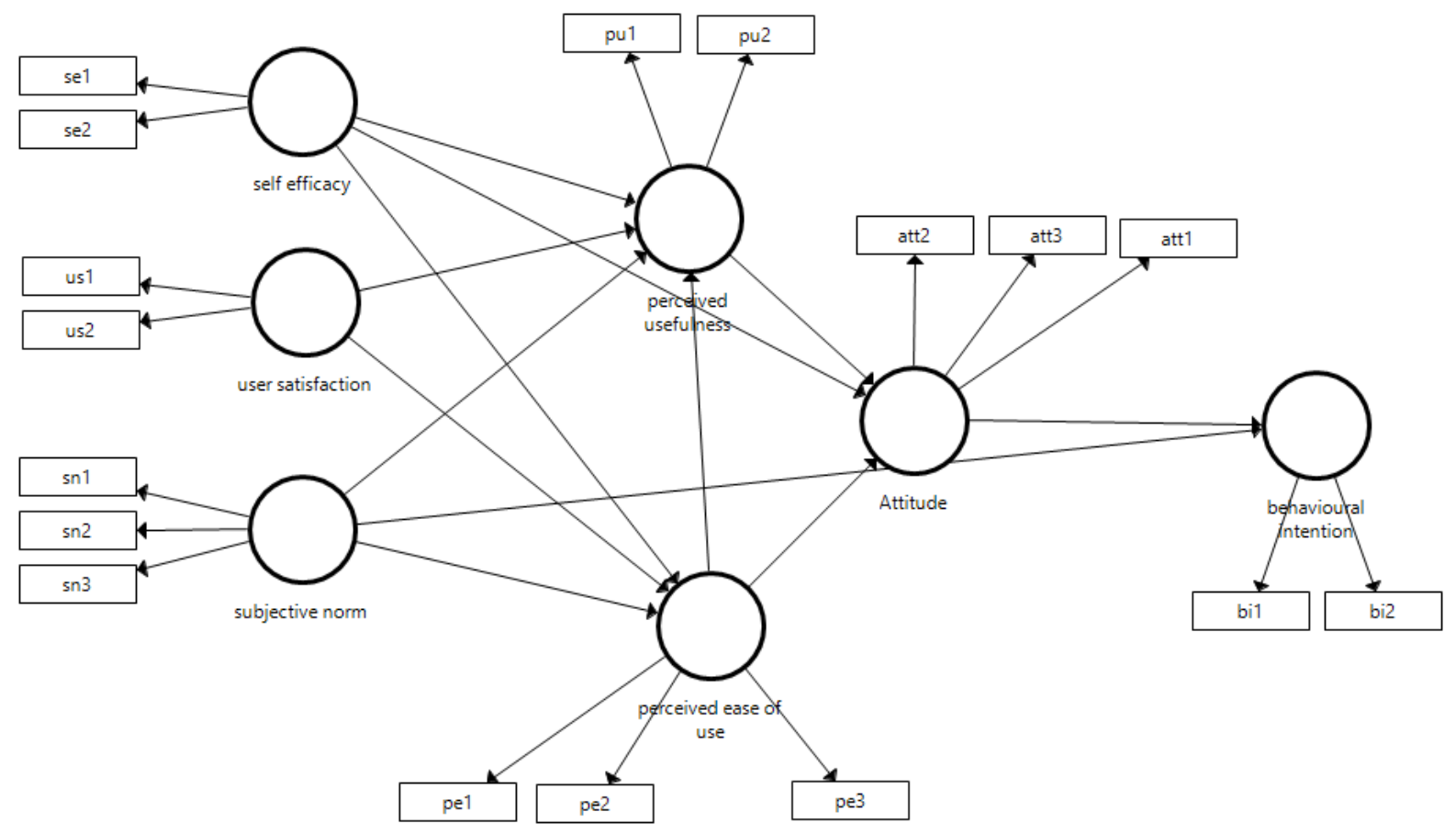

Figure 1: The proposed research model

\section{Self-Efficacy (SE)}

Self-efficacy is one's belief in his or her ability to execute a particular task or behaviour (Bandura, 1986). Venkatesh and Davis (2000) found that SE acts as a determinant of perceived ease of use both before and after hands-on use with a system. SE is considered as one of the external variables in the TAM model and it plays a vital role in shaping an individual's feeling and behaviour (Compeau \& Higgings, 1995). Research on self-efficacy has been found to be a significant predictor of perceived usefulness and perceived ease of use (e.g., Hsu et al., 2009; Macharia \& Pelser, 2014; Padilla-Melendez et al., 2008).

Moreover, Eastin (2002) revealed that SE has a significant impact on customer attitude and played important role in the e-commerce adoption processes. Also, Hanudin (2007) found that there is a causal link between SE and perceived ease of use. In fact, SE would lead to more favourable behavioural intention through its influence on perceived usefulness and perceived ease 
of use (Pikkarainen, Pikkarainen, Karjaluoto, \& Pahnila, 2004; Wang, Wang, Lin, \& Tang, 2003). Mungania and Reio (2005) found a significant relationship between dispositional barriers and elearning self-efficacy. The authors argued that educational practitioners should take into consideration the learners' dispositions and find ways to improve students' self-efficacy. In their study, Grandon et al. (2005) found that e-learning self-efficacy has an indirect effect on students' intentions through perceived ease of use. Other TAM researchers have found an influence of SE on different TAM variables (Chen, Huang, \& Shih, 2002; Downey, 2006; Saadé \& Kira, 2009; Strong, Deneen, \& Ng, 2006). As a result, this study hypothesizes the following:

\section{H1: Self-efficacy has a significant effect on perceived ease of use of using MyMath-} Lab.

H2: Self-efficacy has a significant effect on perceived usefulness of using MyMathLab.

H3: Self-efficacy has a significant effect on attitude towards using MyMathLab.

\section{Subjective Norm (SN)}

Subjective norm, one of the social influence variables, refers to the perceived social pressure to perform or not to perform certain behaviour (Ajzen, 1991). SN is defined as the person's perception that most people who are important to him or her think he or she should or should not perform the behaviour in question (Davis, 1989). SN was adopted and included in the TAM model, in order to overcome the limitation of TAM in measuring the influence of social environments (Venkatesh \& Davis, 2000). Whether this is positive or negative, it is a very important factor in many aspects of the lives of citizens and is likely to be influential (Venkatesh et al., 2003). It is believed that, in some cases, people might use a system to comply with the mandates of others rather than their own feelings and beliefs (Davis, 1989).

From the theory of planned behaviour (Ajzen, 1991) and unified theory of acceptance and use of technology (Venkatesh et al., 2003), subjective norm (or social influence) was hypothesised to have a direct effect on behavioural intention and perceived usefulness. Venkatesh and Davis (2000) argued that when a person's co-worker thought that the system was useful, the person was likely to have the same idea. It is argued that people can choose to perform a specific behaviour even if they are not positive towards the behaviour or its consequences, depending on how important they think that the important referents believe that they should act in a certain way (Fishbein \& Ajzen 1975; Venkatesh \& Davis 2000). This was supported by Schepers and Wetzels (2007), who meta-analysed 88 studies on the relationship between subjective norm and the TAM variables. They found overwhelming evidence that showed a significant relationship between subjective norm and perceived usefulness, and subjective norm and intention to use.

In their study, Grandon et al. (2005) found subjective norm to be a significant factor in affecting university students' intention to use e-learning. Findings of many scholars (e.g., Lu et al., 2003; Pavlou et al., 2003; Rogers, 1995; Taylor \& Todd, 1995) suggest that social influence is an important determinant of behaviour. Hence, this study hypothesizes the following:

H4: Subjective norm has a significant effect on perceived ease of use of MyMathLab.

H5: Subjective norm has a significant effect on perceived usefulness of using MyMathLab.

H6: Subjective norm has a significant effect on intention towards using MyMathLab. 


\section{Satisfaction}

Student satisfaction is an important indicator of the quality of learning experiences students received (Yukselturk \& Yildirim, 2008). Hence, it is valuable to investigate students' satisfaction with different technology used in the learning and teaching process, as new technologies have altered the way in which students interact with instructors and classmates (Kaminski, Switzer, \& Gloeckner, 2009). Satisfaction in a given situation is a person's feelings or attitudes toward a variety of factors affecting that situation (Wixom \& Todd, 2005). As articulated in the theory of reasoned action (TRA), these relationships will be predictive of behaviour when the attitude and belief factors are specified in a manner consistent with the behaviour to be explained in terms of time, target, and context (Fazio \& Olson, 2003).

In this paper, we follow the same notation of Wixom and Todd $(2005$, p. 90$)$ in relation to satisfaction, where satisfaction with the system will influence perceptions of usefulness. That is, the higher the overall satisfaction with the system, the more likely one will find the application of that system useful in enhancing his/her work performance. Additionally, the authors argued that satisfaction represents a degree of favourableness with respect to the system and the mechanics of interaction. That is, the more satisfied one is with the system itself, the more likely one is to find the system to be easy to use. The authors argued that influences of object-based attitudes on behavioural beliefs are demonstrated by the strong significant relationships between satisfaction and usefulness, and between satisfaction and ease of use (p. 100).Hence, this study hypothesizes the following:

H7: Students satisfaction has a significant effect on perceived ease of use. H8: Students satisfaction has a significant effect on perceived usefulness of use.

\section{Perceived Usefulness}

Perceived usefulness is defined as the extent to which a person believes that using a particular system will enhance his or her job performance (Davis, 1989). Subramanian (1994) found that perceived usefulness had significant correlation with attitude toward usage behaviour. This finding was later confirmed by Fu, Farn, and Chao (2006) and Norazah, Ramayah, and Norbayah (2008) who found that behavioural intention was largely driven by perceived usefulness. There has been an extensive body of literature in the IS community that provides evidence of the significant effect of perceived usefulness on usage intention (e.g., Taylor \& Todd, 1995; Venkatesh \& Davis, 2000). Selim (2003) investigated the course website acceptance model (CWAM) and tested the relationships among perceived usefulness, perceived ease of use, and intention to use with university students. The authors argued that the model fit the collected data and that the usefulness and ease of use turned out to be good determinants of the acceptance and use of a course website. Also, Liu et al. (2009) concluded that e-learning presentation type and users' intention to use e-learning were related to one another, and concentration and perceived usefulness were considered intermediate variables. Park (2009) found that perceived usefulness and perceived ease of use were found significant in affecting user attitude. Other studies have also provided evidence showing that perceived usefulness has influences on attitudes and intention to use technology (Teo, 2008, 2011a; Yuen, 2002).As a result, this study hypothesizes the following:

\section{H9: Perceived usefulness has a significant effect on attitude towards using MyMathLab.}

\section{Perceived Ease of Use}

Perceived ease of use is another major determinant of attitude toward use in the TAM model. Davis $(1989$, p. 320) defined Perceived Ease of Use (PEU) as "the degree to which a person believes that engaging in online transactions would be free of effort." PEU is the fundamental de- 
terminant for the acceptance and use of IT in general (Moon \& Kim, 2001). This finding was later confirmed by other researchers (e.g., Fagan, Wooldridge, \& Neill, 2008; Hsu et al., 2009; Jahangir \& Begum, 2008; Ramayah, Chin, Norazah, \& Amlus, 2005) who found PEU to have positively influenced the behavioural intention to use different IS applications. More specifically, perceived ease of use was found to be significant construct in e-learning literature (e.g., Lee et al., 2005; Liu et al., 2005; Park, 2009; Selim, 2003). Additionally, Park (2009), in his study of understanding university students' behavioural intention to use e-learning, found that perceived usefulness and perceived ease of use were related to one another. Other studies have also offered support to the direct influence of perceived ease of use on perceived usefulness (e.g., Teo, 2008; Teo, 2011a). These results suggest the following hypotheses:

H10: Perceived ease of use has a significant effect on students' attitude towards using MyMathLab.

H11: Perceived ease of use has a significant effect on the perceived usefulness of MyMathLab.

\section{Attitude}

Karjaluoto, Mattila, and Pento (2002) defined attitude as the one's desirability to use the system. Fishbein and Ajzen (1975) classified attitude into two constructs: attitude toward the object and attitude toward the behaviour. The latter refers to a person's evaluation of a specified behaviour. In TAM context, attitude is defined as the mediating affective response between usefulness and ease of use beliefs and intentions to use a target system (Suki \& Ramayah, 2010). Davis (1989) stated that one's overall attitude toward using a given system is an antecedent to intentions to use. A student's behavioural intention can be caused by his/her feelings about the system. If the students do not like the system or if they feel unpleasant when using it, they will probably want to replace the system with a new one. Many researchers (e.g., Lee et al., 2005; Liu et al., 2009) have demonstrated that attitude is a direct determinant of behavioural intention. Thus, to investigate the effect of students' attitude on their acceptance and usage of MyMathLab, this study hypothesizes that:

\section{H12: Attitude has a significant effect on students' behavioural intention to use MyMathLab}

\section{Method}

\section{Study Context and Participants}

The sample in this study consisted of 228 university students enrolled in remedial and college algebra classes at a Middle Eastern private American University. The students were enrolled in the spring semester of 2015 in four different sections, two remedial and two college algebra classes that were taught by two different instructors. Participants were admitted to the university based on their high school GPA. They were pursuing different fields of study, for example, graphic design, communication, business, computer science, engineering, and some were undecided. Participants had to take remedial math as a preparatory course, which is a not for credit class. On the other hand, college algebra is a three credit class that is a general requirement course. It is one of two math classes that non-science major students should take. Although it is counted in the GPA of the computer sciences and engineering students, it is not counted as one of the math required courses.

All students had to use MyMathLab. Students were assigned the homework through MyMathLab and had the option to access the homework more than once. MyMathLab walked them through the problems step by step until they reached a correct final solution. Most importantly, Mymath- 
Lab does not require a lot of training for either students or faculty. Students are usually introduced to MyMathLab in the first period of the semester and get one-to-one help from the instructor should the need arise. The instructor, in turn, gets the training from the publisher or a colleague who is a user of MyMathLab. The instructor goes over the main important features of it, and afterwards it is a simple task for students to access the website and learn more about MyMathLab. One drawback of MyMathLab is that students cannot show the steps of their work.

The questionnaire was distributed to students by their instructors who asked the students to fill out the survey and drop it in their department mailboxes. It was clearly stated on the instruction page of the questionnaire that participation in this survey was voluntary and would not affect students' grades. Students' participation rate was very high; 228 students out of 240 participated and answered all questions. None of the 240 students dropped the class; probably the students who did not participate in the study were absent the day the survey was distributed or they did not have any interest to participate. Data were collected during the last week of classes to guarantee that students had obtained enough experience with the system before they answered the questionnaire questions.

Tables 1, 2, 3, and 4 provide the information on student gender, student age, student years of study, and student marital status, respectively. The information represented in Table 3 refers to number of years students have been going to the university; it does not necessarily represent whether the student is freshman, sophomore, junior, or senior. Table 4 indicates the number of married and single students. It was found that 21 students were married.

Table 1: Student gender

\begin{tabular}{lll}
\hline & Frequency & Percent \\
\hline Male & 62 & 27.2 \\
Female & 166 & 72.8 \\
Total & 228 & 100 \\
\hline
\end{tabular}

Table 2: Student age

\begin{tabular}{lll}
\hline & Frequency & Percent \\
\hline Less than 18 & 17 & 7.5 \\
$18-25$ & 195 & 85.5 \\
$26-30$ & 7 & 3.1 \\
More than 30 & 9 & 3.9 \\
Total & 228 & 100 \\
\hline
\end{tabular}

Table 3: Student years of study

\begin{tabular}{lll}
\hline & Frequency & Percent \\
\hline one year & 125 & 54.8 \\
Two years & 66 & 28.9 \\
Three years & 21 & 9.2 \\
Four years & 16 & 7.1 \\
Total & 228 & 100 \\
\hline
\end{tabular}


Table 4: Student marital status

\begin{tabular}{lll}
\hline & Frequency & Percent \\
\hline Single & 207 & 90.8 \\
Married & 21 & 9.2 \\
Total & 228 & 100 \\
\hline
\end{tabular}

\section{Measures}

The instrument used in this study integrates the technology acceptance model (TAM) that was created by Davis (1989) as shown in Figure 2 and user satisfaction. Park (2009) has used TAM with seven constructs: self-efficacy, subjective norm, system accessibility, perceived usefulness, perceived ease of use, attitude, and intention to use (Figure 3). In this study, all of the above constructs except system accessibility were used. In addition, a user satisfaction construct was used. Satisfaction was measured by two indicators using a 7-point Likert-type scale. Those indicators were used by Wixom and Todd (2005). The indicators were "All things considered, I am very satisfied with MyMathLab," "Over all my interaction with MyMathLab is very satisfying." The subjective norm indicators were "What MyMathLab stands for is important for me as a university student," "I like using MyMathLab on the similarity of my values and society values underlying its use," "In order to prepare me for future job, it is necessary to take MyMathLab courses." The self-efficacy indicators were "I feel confident finding information on MyMathLab webpage," and "I have the necessary skills for using MyMathLab." The behavioural intention indicators were "I intend to check announcements from MyMathLab frequently," "I intend to be a heavy user of MyMathLab." The attitude constructs were "studying through MyMathLab was a good idea," "studying through MyMathLab was a wise idea," and "I am positive toward MyMathLab". The perceived usefulness indicators were "MyMathLab would improve my learning performance," and "MyMathLab could make it easier to study course content." The perceived ease of use indicators were "I find MyMathLab system easy to use," "Learning how to use MyMathLab is easy for me," and "It is easy to become skilful at using MyMathLab." The arrows between a construct and its corresponding indicators symbolize measurement validity.

The statistical software Smart-PLS 3.1 that implements the use of partial least square structural equation modelling (PLS-SEM) method was used to conduct the statistical analysis in this study. (PLS-SEM) is a variance based method used to estimate structural equation models. Other wellknown software such as LISREL and AMOS are covariance based that use the maximum likelihood approach to estimate structural equation models. The advantage of using PLS-SEM lies in the fact that no assumption on the distribution of data is needed (Cassel, Hackl, \& Westlund, 1999). Moreover, a sample size that is 10 times the largest number of indicators is required. The sample size in this study is 228 which is more than what is required because the largest number of indicators is three. This large sample size will increase the consistency of the model estimations. The indicators in the proposed model are all reflective because they are considered as effects of the latent variables (Bollen \& Lennox, 1991). 


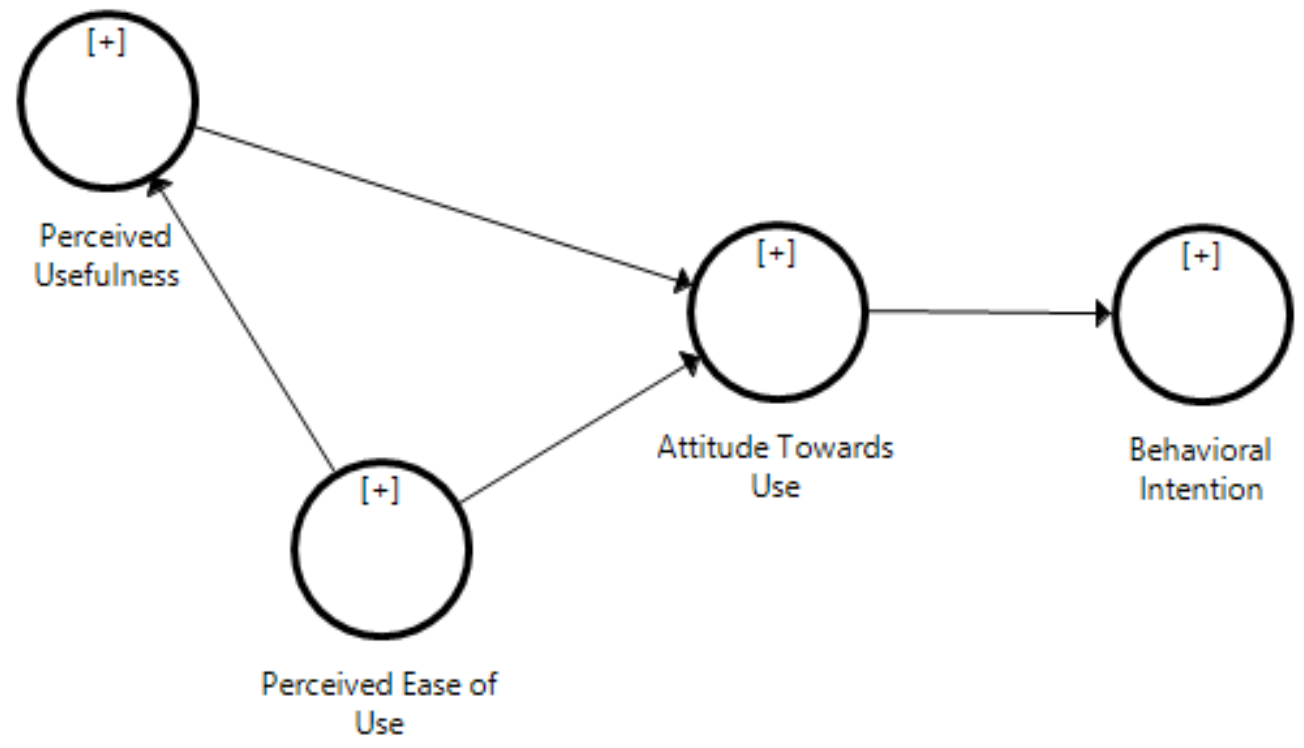

Figure 2: Original TAM (Davis, 1989)

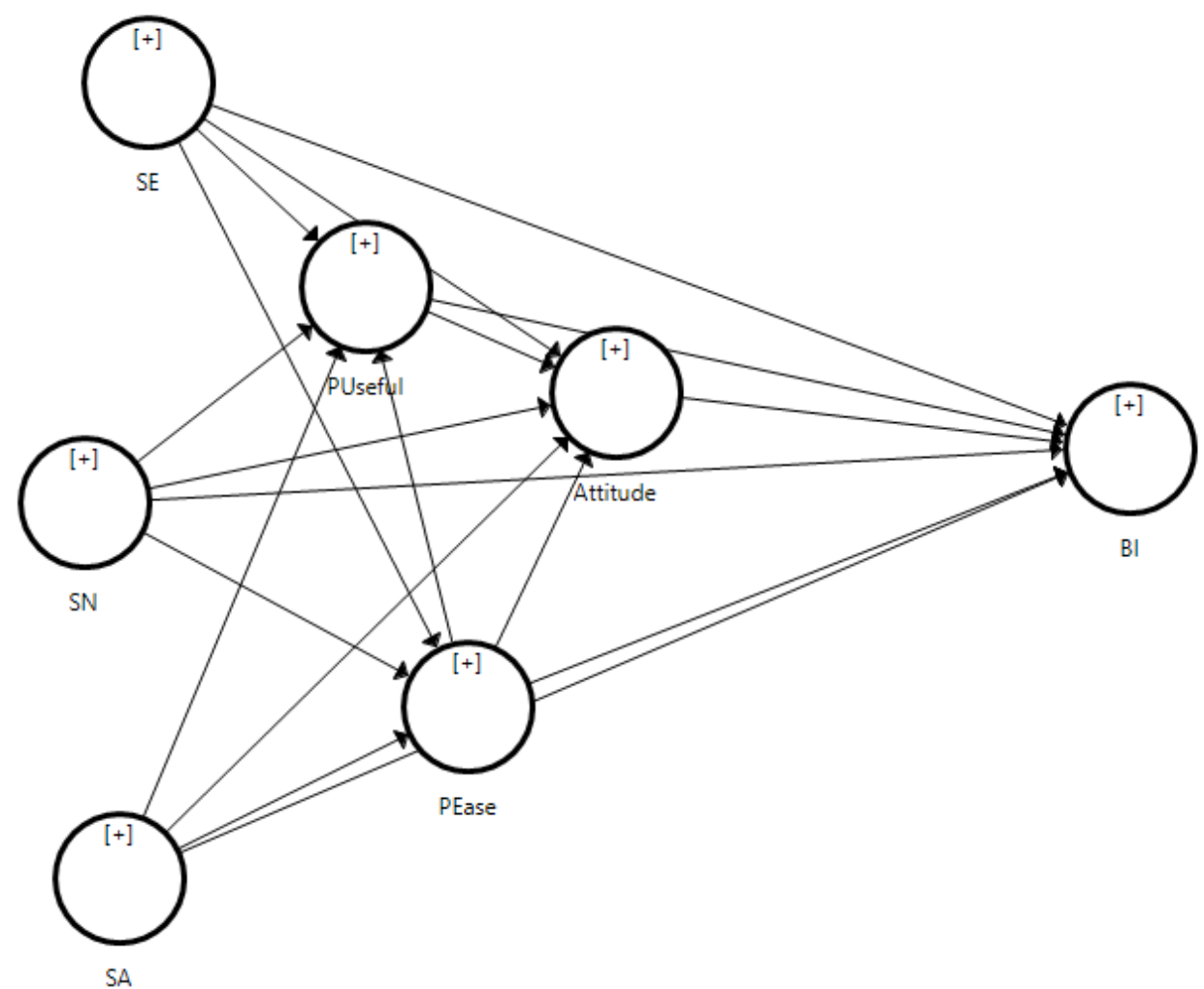

Figure 3: Park's Model (Park, 2009)

\section{Results}

In order to assess the measurement model, the composite reliability, convergent validity and discriminant validity should be evaluated (Barclay, Higgins, \& Thompson, 1995). The composite reliability estimates the reliability based on the inter-correlations of the indicator variables of a specific construct. It is recommended that the value does not exceed 0.95 , otherwise, the indica- 
tors will be measuring same information (Nunnally \& Bernstein, 1994). Construct reliability for all constructs in this model ranged between 0.90 and 0.94 as shown in Table 5. Convergent validity measures the positive correlation between an indicator and the other indicators of a construct. It can be measured by using the average value extracted measure (AVE) that should exceed 0.5 . Table 6 shows that all values in this model varied between 0.75 and 0.90 . Discriminant validity measures the extent to which a latent variable is distinct from other variables. One way to assess discriminant validity is by using the Fornell-Larcker criterion (Fornell \& Larcker, 1981). It requires that the square root of each construct's (AVE) be higher than all its correlation with the other constructs. Table 7 shows that all diagonal values (square root of AVE) are higher than those in their corresponding rows and columns.

Table 5: Composite Reliability

\begin{tabular}{lc}
\hline & Composite reliability \\
\hline attitude (ATT) & 0.94 \\
behavioral intention (BI) & 0.92 \\
perceived ease of use (PE) & 0.94 \\
perceived usefulness (PU) & 0.94 \\
self efficacy (SE) & 0.90 \\
subjective norm (SN) & 0.90 \\
user satisfaction (US) & 0.94 \\
\hline
\end{tabular}

Table 6: Average value extracted

\begin{tabular}{ll}
\hline & AVE \\
\hline attitude & 0.855 \\
behavioural intention & 0.855 \\
perceived ease of use & 0.859 \\
perceived usefulness & 0.904 \\
self efficacy & 0.832 \\
subjective norm & 0.757 \\
user satisfaction & 0.888 \\
\hline
\end{tabular}

Table 7: Latent variable correlation

\begin{tabular}{llllllll}
\hline & ATT & BI & PE & PU & SE & SN & US \\
\hline ATT & $\mathbf{0 . 9 2 5}$ & & & & & & \\
BI & 0.517 & $\mathbf{0 . 9 2 5}$ & & & & & \\
PE & 0.724 & 0.425 & $\mathbf{0 . 9 2 7}$ & & & & \\
PU & 0.828 & 0.437 & 0.696 & $\mathbf{0 . 9 5 1}$ & & & \\
SE & 0.73 & 0.53 & 0.661 & 0.714 & $\mathbf{0 . 9 1 2}$ & & \\
SN & 0.682 & 0.607 & 0.601 & 0.655 & 0.733 & $\mathbf{0 . 8 7}$ & \\
US & 0.603 & 0.352 & 0.621 & 0.632 & 0.627 & 0.561 & $\mathbf{0 . 9 4 3}$ \\
\hline
\end{tabular}

The results of the hypothesis testing are shown in Table 8 . Twelve hypotheses were tested in this model and it was found a few of them were significant at the 0.05 significance level and the majority at the 0.00 significance level. Table 8 shows the path coefficients, $t$ statistics and $p$-values. The results indicate that perceived usefulness had the strongest influence $(\beta=0.526, p<.001)$ on attitude, followed by subjective norm on behavioral intention $(\beta=0.475, p<.001)$. The direct influence of user satisfaction on perceived ease was also influential $(\beta=0.308, p<.001)$. Other direct and indirect effects on behavioral intention were also significant. 
Table 8: Hypotheses testing results

\begin{tabular}{lcccl}
\hline & Models' coefficients $\beta$ & T Statistics & P Values & Results \\
\hline H1: ATT -> BI & 0.193 & 2.763 & 0.006 & Support the hypothesis \\
H2: PE -> Attitude & 0.219 & 2.814 & 0.005 & Support the hypothesis \\
H3: PE -> PU & 0.299 & 3.805 & 0 & Support the hypothesis \\
H4: PU -> ATT & 0.526 & 7.065 & 0 & Support the hypothesis \\
H5: SE -> ATT & 0.21 & 3.154 & 0.002 & Support the hypothesis \\
H6: SE -> PE & 0.333 & 3.9 & 0 & Support the hypothesis \\
H7: SE -> PU & 0.282 & 3.97 & 0 & Support the hypothesis \\
H8: SN ->BI & 0.475 & 6.712 & 0 & Support the hypothesis \\
H9: SN -> PE & 0.184 & 2.336 & 0.02 & Support the hypothesis \\
H10: SN -> PU & 0.17 & 2.226 & 0.026 & Support the hypothesis \\
H11: US -> PE & 0.308 & 4.28 & 0 & Support the hypothesis \\
H12: US -> PU & 0.174 & 2.527 & 0.012 & Support the hypothesis \\
\hline
\end{tabular}

Figure 4 provides the values of the outer loadings. All values lie above the threshold value of 0.708 . They vary from 0.782 to 0.951 .It also shows the squared multiple correlation $R^{2}$ for all endogenous variables. The SEM explained substantial variance in attitude $R^{2}=0.747$, in perceived usefulness $R^{2}=0.631$, in perceived ease of use $R^{2}=0.522$ and in behavioural intention $R^{2}=0.388$.

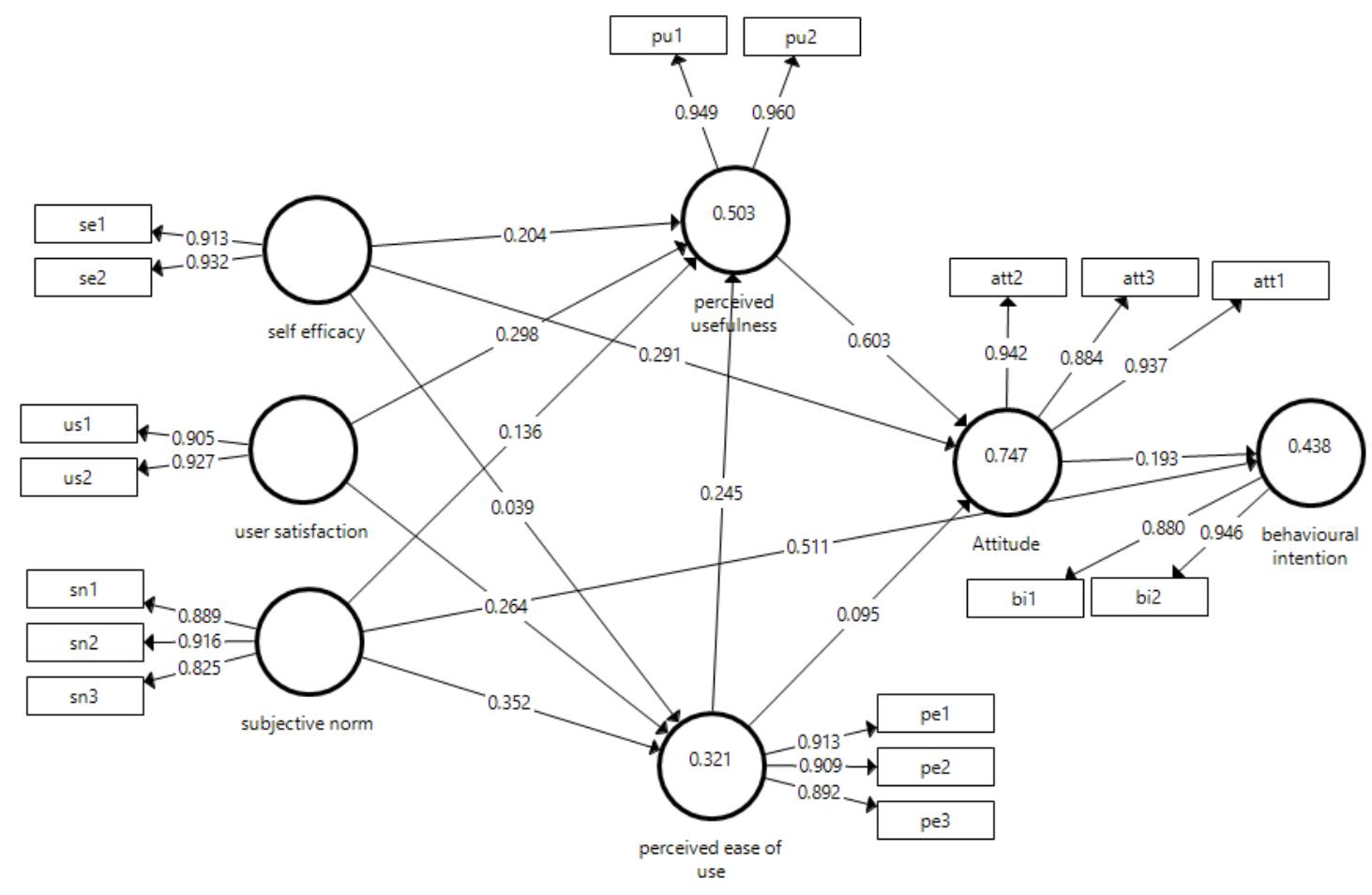

Figure 4: The PLS proposed model 


\section{Discussion}

Previous research and this study showed that TAM is a useful theoretical model that helps to understand student perceptions of technology use in learning. This study tested the model using students' acceptance of MyMathLab. The results showed that the exogenous variables user satisfaction, subjective norm, self-efficacy, perceived ease of use, perceived usefulness, and attitude positively affected the endogenous variable behavioural intention. The reported results are in line with what is found in literature and can be explained based on motivational theory (Lee et al., 2005; Park, 2009; Saddé et al., 2007). Although the composite reliability values for some of the constructs is close to 0.95 , this is still considered acceptable. High values have been reported in the literature. For example, Park (2009) reported a value of 0.93 and 0.94 for perceived ease of use and attitude, respectively. The reason for such high values could be that participants could not fully differentiate between the indicators of the considered construct. Probably this issue could be solved in a future work by rephrasing the questions.

One interesting finding is that user satisfaction plays important role on perceived ease of use, $\beta=0.308$. Wixom and Todd's (2005) model justifies the findings, and as articulated in the theory of reasoned action (TRA), these relationships will be predictive of behaviour when the attitude and belief factors are specified in a manner consistent with the behaviour to be explained in terms of time, target, and context (Fazio \& Olson, 2003). User satisfaction is one of the main constructs in this study and the one that makes it special in the field of education. The important effect of user satisfaction on perceived ease of use is obvious in this study, and for this reason teaching institutions are encouraged to adopt technological tools that are already in place and satisfied the users. Moreover, it is important that students are introduced to the new tools in an efficient way with hands on experience to ensure that they are fully satisfied with the new tool and its value to their education. The model and the empirical results showed that when students are satisfied with MyMathLab and interact well with this tool they find it easy for them to use it and become skilful at using it. The satisfaction and ease of use feeling indirectly affect students' behavioural intention to use. Once they are satisfied with MyMathLab, students might probably find the system easy to use and perform well.

Subjective norm is another important construct that affects the intention to use technology. It is found in this study that subjective norm has the second largest significant effect on intention to use as well as a direct effect on perceived ease of use and perceived usefulness. Based on Venkatesh et al. (2003), subjective norm is a very important and influential factor in the life of citizens. As subjective norm is affected by the social influence around the person, faculty members seem to have a great role to play aside from teaching their students. They should inform their students about the value of such technological tools to their education as well as to their future careers. They should advertise these technological tools and offer more classes that are related to them.

\section{Conclusions and Limitations}

The purpose of this work was to integrate user satisfaction in TAM as one of the external variables and to empirically test the model. The current study contributes to the ongoing research on TAM by introducing and confirming the influence of user satisfaction as an external variable on the user's intention to use the e-learning technology, MyMathLab. Finding of this research should encourage institutions to put more emphasis on implementing more technological tools in the learning process of mathematics. In general, the empirical results supported the model, they demonstrate that students will use MyMathlab if they perceive it to be useful to them and if they perceive that the tool is easy to use and supports their educational needs. Probably, students welcomed the adoption of MyMathLab as a part and tool of the learning process. Perceived useful- 
ness as defined by Davis (1989) is the extent to which a person believes that using a particular system will enhance the job. The high effect of the perceived usefulness construct on attitude can be explained by students' interest in MyMathLab and viewing it as useful technological tool that might enhance their learning. It seems that students are motivated both intrinsically and extrinsically as they seem to value the role that technological tools will play either on the personal level or on the social level. It is not only beneficial to them as students, but it will also please others, such as parents and teachers, to know that such tools had a big influence on their education.

Last but not least, this research study examined the applicability of the integration of TAM and user satisfaction to explain students' acceptance of the platform MyMathLab as part of their enrolment in mathematics classes at university. It was an attempt in the field of education that combines the user satisfaction construct with TAM. The findings have great implications for educators and students all over the world as they shed light on the significant factors that determine students' acceptance and satisfaction with technological tools or platforms used in the math classroom.

Despite the findings of this study, it is essential to remember that it was limited to students in a private American university in the Middle East. Perception of students may differ as institution type impacts the educational system. It is recommended that same study be done at different institutions in the region, public and private, before any generalization can be made. It would also be interesting to test a variety of platforms other than MyMathLab. Another limitation of this study was the number of participants. It is recommended that future research be extended to include more participants. This study is also limited to the remedial and college algebra classes and it is not clear whether student perceptions of technology use in math learning would be different at higher level classes. Therefore, it is recommended to extend this work to include higher level math courses. More constructs are recommended to be included in future work, as suggested by Davis (1993) such as student experience, technical support, and others. Thus, future work should examine different external variables more closely. Identifying these variables is beneficial for understanding students' concerns and identifying ways to improve MyMathLab. Moreover, by integrating more variables into the proposed model, teachers and administration can identify where students have difficulties with MyMathLab and what obstacles need to be removed to increase acceptance and usage among students.

\section{References}

Adesina, A., \& Ayo, K. (2010). An empirical investigation of the level of user's acceptance of e-banking in Nigeria. Journal of Internet Banking and Commerce, 15(1), 1-13.

Al-Adwan, A., Al-Adwan, A., \& Smedley, J. (2013). Exploring students' acceptance of e-learning using Technology Acceptance Model in Jordanian universities. International Journal of Education and Development using Information and Communication Technology, 9(2), 4-18.

Al-hawari, M. A., \& Mouakket, S. (2010). The influence of technology acceptance model (TAM) factors on students' e-satisfaction and e-retention within the context of UAE e-learning. Education, Business and Society: Contemporary Middle Eastern, 3(4), 299-314.

Al-Shafi, S., \&Weerakkody, V. (2009). The use of wireless internet parks to facilitate adoption and diffusion of e-government services: An empirical study in Qatar. Proceedings of the $14^{\text {th }}$ Americas Conference on Information Systems (AMCIS 2008), Toronto, Ontario.

Agarwal, R., \& Prasad, J. (1998). A conceptual and operational definition of personal innovativeness in the domain of information technology. Information Systems Research, 9(2), 204-215.

Ajzen, I. (1991). The theory of planned behaviour. Organizational Behavior and Human Decision Processes, 50(2), 179-211. 
Bandura, A. (1986). Social functions of thought and action: A social cognitive theory. Upper Saddle River, NJ: Prentice-Hall.

Barclay, D., Higgins, C., \& Thompson, R. (1995). The partial least squares (PLS) approach to causal modeling: Personal computer adoption and use as an illustration. Technology Studies, 2(2), 285-309.

Bollen, K., \& Lennox, R. (1991). Conventional wisdom on measurement: A structural equation perspective. Psychological Bulletin, 110(2), 305.

Cassel, C., Hackl, P., \& Westlund, A. H. (1999). Robustness of partial least-squares method for estimating latent variable quality structures. Journal of Applied Statistics, 26(4), 435-446.

Chen, N. S., Huang, H. Y., \& Shih, Y. C. (2002). Factors affecting usage of Web-based teachers' training in elementary and high school. In Kinshuk, R. Lewis, K. Akahori, R. Kemp, T. Okamoto, L. Henderson, \& C.-H. Lee (Eds), Proceedings of the International Conference on Computers in Education (pp. 589-592). Washington DC: IEEE Computing Society Press.

Compeau, D. R., \& Higgins, C. A. (1995). Computer self-efficacy: Development of a measure and initial test. MIS Quarterly, 19, 189-211.

Dasgupta, S., Granger, M., \& McGarry, N. (2002). User acceptance of e-collaboration technology: An extension of the technology acceptance model. Group Decision and Negotiation, 11(2), 87-100.

Davis, F. D. (1986). A technology acceptance model for empirically testing new end-user information systems: theory and results. (Doctoral dissertation, MIT Sloan School of Management, Cambridge, MA.)

Davis, F. D. (1989). Perceived usefulness, perceived ease of use, and user acceptance of information technology. MIS Quarterly, 13(3), 319-339.

Davis, F.D. (1993). User acceptance of information technology system characteristics: User perceptions and behavioral Impacts. International Journal of Man-Machine Studies 38(3), 475-487.

Davis, F. D., Bagozzi, R. P., \&Warshaw, P. R. (1989). User acceptance of computer technology: A comparison of two theoretical models. Management Science, 35(8), 982-1003.

Drennan, J., Kennedy, J., \& Pisarski, A. (2005). Factors affecting student attitudes toward flexible online learning in management education. The Journal of Educational Research, 98(6), 331-338, 384.

Downey, J. (2006). Measuring general computer self-efficacy: The surprising comparison of three instruments in predicting performance, attitudes, and usage. In R. Sprague (Ed.), Proceedings of the 39th Hawaii International Conference on System Sciences (Vol. 8, pp. 210-220). Washington DC: IEEE Computing Society Press.

Eastin, M. S. (2002), Diffusion of e-commerce: An analysis of the adoption of four e-commerce activities. Telematics and Informatics, 19(3), 251-267.

Elwood, S., Changchit, C., \& Cutshall, R. (2006). Investigating students' perceptions on laptop initiative in higher education: An extension of the technology acceptance model. Campus - Wide Information Systems, 23(5), 336-349.

Escobar-Rodriguez, T., \& Monge-Lozano, P. (2012). The acceptance of Moodle technology by business administration students. Computers\& Education, 58, 1085-1093.

Fagan, M. H., Neill, S., \& Wooldridge, B. R. (2008). Exploring the intention to use computers: An empirical investigation of the role of intrinsic motivation, extrinsic motivation, and perceived ease of use. Journal of Computer Information Systems, 48(3), 31-37.

Fazio, R. H., \& Olson, M. A. (2003). Implicit measures in social cognition: Their meaning and use. Annual Review of Psychology, 54, 297-327.

Fishbein, M., \&Ajzen, I. (1975). Belief, attitude, intention and behavior: An introduction to theory and research. Reading, MA: Addison-Wesley.

Fornell, C., \& Larcker, D. F. (1981). Evaluating structural equation models with unobservable variables and measurement error. Journal of Marketing Research, 39-50. 
Fu, J. R., Farn, C. K., \& Chao, W. P. (2006). Acceptance of electronic tax filing: A study of taxpayer intentions. Information \& Management, 43, 109-126.

Gibson, S., Harris, M., \& Colaric, S. (2008). Technology acceptance in an academic context: Faculty acceptance of online education. Journal of Education for Business, 83(6), 355-359.

Grandon, E., Alshare, O., \& Kwan, O. (2005). Factors influencing student intention to adopt online classes: A cross-cultural study. Journal of Computing Sciences in Colleges, 20(4), 46-56.

Hanudin, A. (2007). Internet banking adoption among young intellectuals. Journal of Internet Banking and Commerce, 12(3). Retrieved from http://www.arraydev.com/commerce/jibc

Hsu, M. K.., Wang S. W., \& Chiu, K. K. (2009). Computer attitude, statistics anxiety and self-efficacy on statistical software adoption behavior: An empirical study of online MBA learners. Computers in $\mathrm{Hu}$ man Behavior, 25, 412-420.

Imtiaz, M. A., \& Mirhashemi, M. T. (2013). Analyzing trends in technology acceptance studies in education domain. In Current Trends in Information Technology (CTIT), 2013 International Conference on (pp. 23-27). IEEE.

Jahangir, N., \& Begum, N. (2008). The role of perceived usefulness, perceived ease of use, security and privacy, and customer attitude to engender customer adaptation in the context of electronic banking. African Journal of Business Management, 2(1), 32-40.

Kaminski, K., Switzer, J., \& Gloeckner, G. (2009). Workforce readiness: A study of university students' fluency with information technology. Computers \& Education, 53(2), 228-233.

Karjaluoto, H., Mattila, M., \& Pento, T. (2002). Factors underlying attitude formation towards online banking in Finland. International Journal of Bank Marketing, 20(6), 261-272.

Kiliç, E. (2014). Determining the factors of affecting the Moodle use by using TAM. The story of a university after a destructive earthquake. Hacettepe Üniversitesi Eğitim Fakültesi Dergisi, 29(1), 169-179.

Lee, M. K. O., Cheung, C. M. K., \& Chen, Z. (2005). Acceptance of Internet-based learning medium: The role of extrinsic and intrinsic motivation. Information \& Management, 42, 1095-1104.

Legris, P., Ingham, J., \& Collerette, P. (2003). Why do people use information technology? A critical review of the technology acceptance model. Information \& Management, 40(3), 191-204.

Liu, S., Liao, H. \& Pratt, J. (2009). Impact of media richness and flow on e-learning technology acceptance. Computers\& Education, 52(3), 599-607.

Lu, J., Yu, C. S., Liu, C., \& Yao, J. E. (2003). Technology acceptance model for wireless Internet. Internet Research, 13(3), 206-222.

Macharia, J. K., \& Pelser, T. G. (2014). Key factors that influence the diffusion and infusion of information and communication technologies in Kenyan higher education. Studies in Higher Education, 39(4), 695-709.

Martín-Blas, T., \& Serrano-Fernández, A. (2009). The role of new technologies in the learning process: Moodle as a teaching tool in Physics. Computers \& Education, 52(1), 35-44.

Mathieson, K. (1991). Predicting user intentions: Comparing Technology Acceptance Model with the Theory of Planned Behaviour. Information Systems Research, 2(3), 173-191.

Mathieson, K., Peacock, E., \& Chin, W. W. (2001). Extending the technology acceptance model: The influence of perceived user resources. ACM SigMIS Database, 32(3), 86-112.

Moon, J. W., \& Kim, Y. G. (2001). Extending the TAM for a World-Wide-Web context. Information \& Management, 38(4), 217-230.

Mungania, P., \& Reio, T. G., Jr. (2005). If e-learners get there, will they stay? The role of e-learning selfefficacy. Paper presented at the Academy of Human Resource Development International Conference (AHRD), Estes Park, CO, Feb 24-27, 2005, 1110-1117. 
Ngai, E. W. T., Poon, J. K. L., \& Chan, Y. H. C. (2007). Empirical examination of adoption of WebCT using TAM. Computers and Education, 48(2), 250-267.

Norazah, M. S., Ramayah, T., \& Norbayah, M. S. (2008). Internet shopping acceptance: Examining the influence of intrinsic versus extrinsic motivations. Direct Marketing: An International Journal, 2(2), $97-110$.

Nunnally, J. C., \& Bernstein, I. H. (1994). The assessment of reliability. Psychometric Theory, 3, 248-292.

Padilla-Melendez, A., Garrido-Moreno, A., \& Aguila-Obra, A. R. D. (2008). Factors affecting ecollaboration technology use among management students. Computers and Education, 51,609-623.

Park, S. Y. (2009). An analysis of the Technology Acceptance Model in understanding university students' behavioral intention to use e-Learning. Educational Technology \& Society, 12(3), 150-162.

Pavlou, A. (2003). Consumer acceptance of electronic commerce: Integrating trust and risk with the technology acceptance model. International Journal of Electronic Commerce, 7(3), 101-134.

Phuangthong, D., \& Malisawan, D. (2005). A study of behavioral intention for $3 \mathrm{G}$ mobile internet technology: Preliminary research on mobile learning. Proceedings of the Second International Conference on eLearning for Knowledge-Based Society, August 4-7, 2005, Bangkok, Thailand.

Pikkarainen, T., Pikkarainen, K., Karjaluoto, H., \& Pahnila S. (2004). Consumer acceptance of online banking: An extension of technology acceptance model. Internet Research, 14(3), 224-235.

Ramayah, T., Chin, Y. L., Norazah, M. S., \& Amlus, I. (2005). Determinants of intention to use an online bill payment system among MBA students. E-Business, 9, 80-91.

Rasimah, C. M. Y., Ahmad, A., \& Zaman, H. B. (2011). Evaluation of user acceptance of mixed reality technology. In K. S. Hong \& K. W. Lai (Eds), ICT for accessible, effective and efficient higher education: Experiences of Southeast Asia. Australasian Journal of Education Technology, 27(Special issue, 8), 1369-1387.

Rogers, E. M. (1962). Diffusion of innovations $\left(1^{\text {st }}\right.$ ed.), New York: The Free Press.

Rogers, E. M. (1995). Diffusion of Innovations $\left(4^{\text {th }}\right.$ ed.), New York: The Free Press.

Ruthven, K. (2009). Towards a naturalistic conceptualisation of technology integration in classroom practice: The example of school mathematics. Education \& Didactique, 3(1), 131-152.

Saadé, R., \& Kira, D. (2009). Computer anxiety in e-learning: The effect of computer self-efficacy. Journal of Information Technology Education: Research, 8(1), pp. 177-191. Retrieved from http://www.jite.org/documents/Vol8/JITEv8p177-191Saade724.pdf

Saadé, R., Nebebe, F., \& Tan, W. (2007). Viability of the "Technology Acceptance Model" in multimedia learning environments: A comparative study. Interdisciplinary Journal of E-Learning and Learning Objects, 3(1), 175-184. Retrieved from http://www.ijello.org/Volume3/IJKLOv3p175184Saade393.pdf

Schepers, J., \&Wetzels, M. (2007). A meta-analysis of the technology acceptance model: Investigating subjective norm and moderation effects. Information \& Management, 44, 90-103.

Selim, H. M. (2003). An empirical investigation of student acceptance of course web sites. Computers \& Education, 40, 343-360.

Shah, S. A. M., Iqbal, N., Janjua, S. Y., \&Amjad, S. (2013). Employee behavior towards adoption of elearning courses: Validating Technology Acceptance Model. Mediterranean Journal of Social Sciences, 4(14), 765.

Sharma, S. K., \& Chandel, J. K. (2013).Technology acceptance model for the use of learning through websites among students in Oman. The International Arab Journal of Information Technology, 3(1), 44-49.

Shen, J., \& Eder, L. B. (2009). Intentions to use virtual worlds for education. Journal of Information Systems Education, 20(2), 225-233. 
Shroff, R. H., Deneen, C. C., \& Ng, E. M. W. (2011). Analysis of the technology acceptance model in examining students' behavioural intention to use an e-portfolio system. Australasian Journal of Educational Technology, 27(4), 600-618.

Strong, D. M., DiShaw, M., \& Brady, D. B. (2006). Extending task technology fit with computer selfefficacy. ACM SIGMIS, 37(2-3), 96-107.

Subramanian, G. H. (1994). A replication of perceived usefulness and perceived ease of use measurement, Decision Sciences, 25(5-6), 863-874.

Suki, N. M., \& Ramayah, T. (2010). User acceptance of the e-government services in Malaysia: Structural equation modeling approach. Interdisciplinary Journal of Information, Knowledge, and Management, 5, 395-413. Retrieved from http://www.ijikm.org/Volume5/IJIKMv5p395-413Norazah437.pdf

Sumak, B., Hericko, M., Pusnik, M., \& Polancic, G. (2011). Factors affecting acceptance and use of Moodle: An empirical study based on TAM. Informatica, 35, 91-100.

Sun, H., \& Zhang, P. (2006).The role of moderating factors in user technology acceptance. International Journal of Human-Computer Studies, 64(2), 53-78.

Tabak, F., \& Nguyen, N. T. (2013). Technology acceptance and performance in online learning environments: Impact of self-regulation. MERLOT Journal of Online Learning and Teaching, 9(1), 1-11.

Taylor, S., \& Todd, P. A. (1995). Understanding information technology usage: A test of competing models. Information Systems Research, 6(2), 144-176.

Teo, T. (2008). A path analysis of pre-service teachers' attitudes toward computer use: Applying and extending the technology acceptance model in an educational context. Interactive Learning Environments, 18(1), 65-79.

Teo, T. (2009). Modelling technology acceptance in education: A study of pre-service teachers. Computers\& Education, 52(2), 302-312.

Teo, T. (2010). An empirical study to validate the Technology Acceptance Model (TAM) in explaining the intention to use technology among educational users. International Journal of Information and Communication Technology Education, 6(4), 1-12.

Teo, T. (2011a). Factors influencing teachers' intention to use technology: Model development and test. Computers \& Education, 57, 2432-2440.

Teo, T. (2011b). Technology acceptance in education, research and issues. Rotterdam: Sense Publishers.

Teo, T. (2012). Examining the intention to use technology among pre-service teachers: An integration of the Technology Acceptance Model (TAM) and Theory of Planned Behavior (TPB). Interactive Learning Environments, 20(1), 3-18.

Teo, T. (2013). A comparison of non-nested models in explaining teachers' intention to use technology. British Journal of Educational Technology, 44(3), E81-E84.

Thompson, R., Compeau, R. D., \& Higgins, C. (2006). Intentions to use information technologies: An integrative model. Journal of Organizational and End User Computing, 18(3), 25-47.

Torun, E. D., Ilgaz, H., \& Usluel, Y. K. (2006). Technology acceptance model and teachers' adoption of laptops. Paper presented at the MIT-LINC conference.

Van Raaij, E. M., \& Schepers, J. J. L. (2008). The acceptance and use of a virtual learning environment in China. Computers and Education, 50, 838-852.

Venkatesh, V., \& Davis, F. D. (2000). A model of the antecedents of perceived ease of use: Development and test. Decision Sciences, 27, 451-481.

Venkatesh, V., Morris, M. G., Davis, G. B., \& Davis. F. D. (2003). User acceptance of information technology: Toward a unified view. MIS Quarterly, 27(3), 425-478. 
Waheed, M., \& Jam, F. A. (2010). Teacher's intention to accept online education: Extended TAM model. Interdisciplinary Journal of Contemporary Research in Business, 2(5), 330-344.

Wang, Y. S., Wang, Y. M., Lin, H. H., \& Tang, T. I. (2003). Determinants of user acceptance of internet banking: An empirical study. International Journal of Service Industry Management, 14(5), 501-519.

Wixom, B. H., \& Todd, P. A. (2005). A theoretical integration of user satisfaction and technology acceptance. Information Systems Research, 16(1), 85-102.

Wong, K. T., Teo, T., \& Russo, S. (2012). Influence of gender and computer teaching efficacy on computer acceptance among Malaysian student teachers: An extended technology acceptance model. Australasian Journal of Education Technology, 28(7), 1190-1207.

Wu, X., \& Gao, Y. (2011). Applying the extended technology acceptance model to the use of clickers in student learning: Some evidence from macroeconomics classes. American Journal of Business Education, 4(7), 43-50.

Yuen, A. H. K. (2002). Gender differences in teacher computer acceptance. Journal of Technology and Teacher Education, 10(3), 365-382.

Yukselturk, E., \&Yildirim, Z. (2008). Investigation of interaction, online support, course structure and flexibility as the contributing factors to students' satisfaction in an online certificate program. Educational Technology \& Society, 11(4), 51-65.

\section{Biographies}

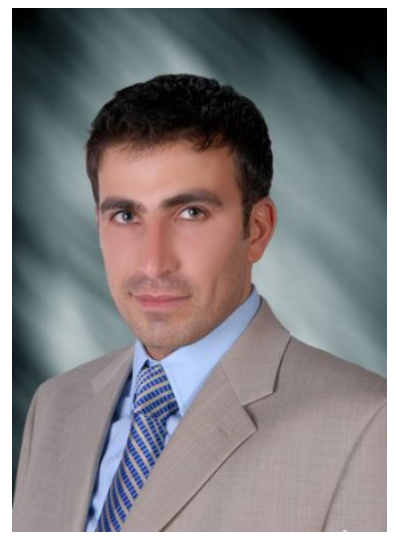

Bashar Zogheib received his Ph.D. in Mathematics from the University of Windsor, Ontario, Canada in 2006 after earning two masters degrees: in Statistics and mathematics from the University of Windsor, Canada. He also earned a masters degree in Mathematics Education from Wayne State University, Michigan, USA. His research and numerous peer reviewed publications focus primarily on computational fluid dynamics, applied statistics and mathematics education. He previously taught at the University of Windsor, Millersville University of Pennsylvania and Nova Southeastern University in Florida. Currently, he is an associate professor and the chair of the Math and Natural Sciences department at the American University of Kuwait.

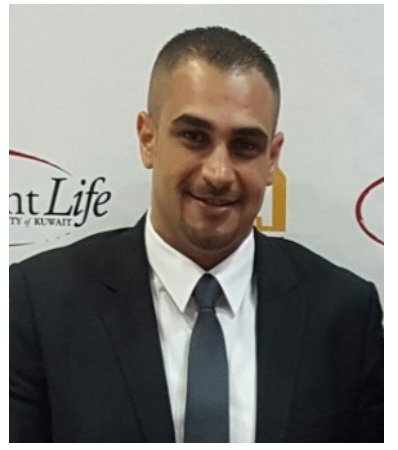

Ahmad A. Rabaa'i is the Department Chair of the Computer Science and Information Systems department at the American University of Kuwait (AUK), Kuwait. Dr. Rabaa'i is an Assisstant Professor of Information System and has published over 25 peer-reviewed articles in conferences and journals including Asia Pacific Journal of Information Systems, Journal of Computers and Information Science, International Journal of Business Information Systems, International Journal of Intercultural Information Management, International Journal of Information Systems and Management, and leading international and regional conferences such as PACIS and ACIS. Dr. Rabaa'i has research interests in service quality and service management, IS success and impact, cultural studies and technology, e-Government, social media and research methods. 


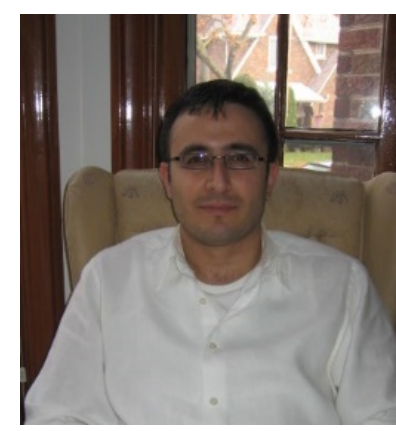

Salah Zogheib received his Ph.D. in Education from the University of Windsor, Ontario, Canada in 2006. His research and numerous peer reviewed publications focus primarily on education and mathematics education. Currently, he is an assistant professor at King Abdulaziz University.

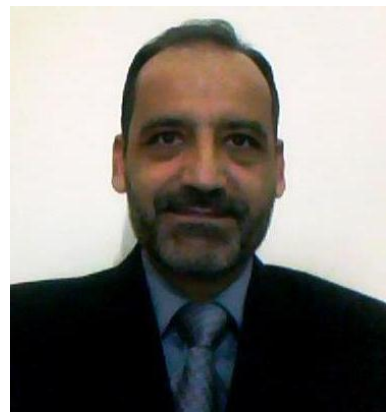

Ali Elsaheli finished an undergraduate degree in Philosophy in 1995 at McMaster University, Hamilton, Ontario. He obtained a M.Sc. in Applied Mathematics in 1999 from the University of Windsor, Ontario. In 2003 he finished all the requirements for the Ph.D. degree in applied Mathematics from the same university. His theses was in Fluid Dynamics and Computational Fluid Dynamics. Besides his interest in Mathematics and Math education, he is greatly interested in Metaphysics, specifically the Perennial Philosophy. 